\title{
НОВЫЙ ФИЛЬТР ДЛЯ ОПРЕДЕЛЕНИЯ КОНЦЕНТРАЦИИ ПЫЛИ В ВОЗДУХЕ
}

\author{
H. М. томсон, \\ действительный член Академии Наук Эстонской ССР
}

Воздух городов загрязняется летучими продуктами сгорания топлива - дымом, сажей, золой и т. д. и разными газообразными и пылевидными отходами производственных процессов, которые в значительной мере ухудшают климатические условия в городах. Нарушение естественного растительного покрова почвы в городах и замена его асфальтом, камнем и железом также изменяет в неблагоприятную сторону климатические факторы и радиационный режим в городах. Облака дыма, постоянно висящие над городом на высоте от 0,5 до 2,0 км, в зависимости от состояния погоды, затемняют солнечный свет и задерживают ультрафиолетовые лучи солнца, которые являются необходимым и важным биологическим фактором внешней среды для всего живого.

Пыль и газы, загрязняюшие воздух, попадают вместе с воздухом при дыхании в легкие, проникают, в некоторой части, во внутреннюю среду организма и своими физическими и химическими свойствами влияют на биохимические процессы в организме. Эффект действия их на организм воочию не всегда может быть заметен из-за ничтожно малых концентраций их в воздухе, но в течение годов и десятилетий они могут привести к понижению сопротивляемости организма и центральной нервной системы вредным внешним влияниям, к появлению хронических заболеваний дыхательных путей и других органов.

Наибольший вред здоровью наносят загрязнения воздуха не непосредственно, а косвенно, рефлекторным путем. Последний путь может привести к понижению функции любого органа и ткани на основе изменения обмена веществ, что также понижает сопротивляемость организма вредным внешним влияниям, инфекциям и другим болезнетворным факторам и делает, таким образом, жизнь менее совершенной, трудоспособность более низкой, болезненные состояния более частыми и длительными и жизнь менее продолжительной.

В социалистических городах неблагоприятные внешние факторы устраняются при планировке и строительстве населенных мест путем правильного выбора места для размещения промышленных районов по отношению к жилым районам, путем усовершенствования технологических процессов производства с целью устранения и уменьшения образования и выделения вредных веществ, путем установки фильтров и уловителей для предохранения выброса в атмосферу вредных примесей и путем введения бездымного способа сжигания топлива, электрификации, 
газификации и теплофикации городов, с расположением источников выработки энергии и сжиганием топлива по возможности вдали от городов.

Забота о состоянии атмосферного воздуха в городах имеет важное социальное значение, так как в городах живет значительная часть населения страны и притом наиболее квалифицированная часть, занятая в производстве, работающая в области науки и политики, которая попадает, таким образом, в менее благоприятные условия, чем трудящиеся, занятые в сельском хозяйстве. Для осуществления контроля и достижения нормального состояния воздуха комиссией Всесоюзной государственной санитарной инспекции выработаны временные нормы предельно допустимых концентраций пыли в атмосферном воздухе в гөродах $0,5 \mathrm{mr} / \mathrm{M}^{3}$ в разовой пробе и $0,15 \mathrm{mr} / \mathrm{m}^{3}$ в среднесуточной пробе, а сажи соответственно $0,15 \mathrm{~m} / \mathrm{m}^{3}$ и $0,05 \mathrm{mr} / \mathrm{m}^{3}$.

Однако удовлетворительного метода определения запыленности воздуха в весовой концентрации на единицу объема воздуха $\left(1 \mathrm{~m}^{3}\right)$ не существует. Применяемый некоторыми авторами способ фильтрации пыли через вату, вставленную в стеклянную трубку, является методом абсолютно неприемлемым вследствие того, что собственная ошибка метода обычно превышает концентрации пыли, находимые в атмосферном воздухе.

Для взвешивания отфильтрованной из воздуха пыли необходимо предварительно довести вату до постоянного веса нагреванием в сушильном шкафу при $105^{\circ}$ в течение 6-24 часов. При сушке ваты уже при $60^{\circ}$ происходят необратимые физико-химические изменения волокна ваты, делающие его более ломким, благодаря чему при аспирации воздуха через вату для фильтрации пыли происходит улетучивание мелких частиц ваты, и поэтому после проведенной аспирации может наблюдаться не только отсутствие привеса, но и уменьшение первоначального веса ваты, что при незначительной запыленности атмосферного воздуха (в пределах нескольких десятых долей миллиграмма на куб. м воздуха) приводит к абсурдному результату. Кроме того, через вату свободно проходят дым и соответствующие размеру частиц дыма пылинки минерального происхождения. Точность взвешивания на аналитических весах равняется $0,2-0,3$ мг, являясь совершенно недостаточной, ибо концентрация пыли в атмосферном воздухе редко превышает десятые доли миллиграмма на куб. м. Фильтр из ваты вполне пригоден при значительной запыленности воздуха, доходящей до десятков и сотен миллиграммов, что наблюдается только при некоторых производственных процессах. В этих случаях ошибка за счет вылетевших частиц ваты в количестве нескольких десятых долей миллиграмма не играет существенной роли.

Взамен ватного фильтра для определения содержания пыли в атмосферном воздухе предлагается новый фильтр, принцип действия которого основан на аэродинамических законах. Фильтр (рис. 1) представляет собой стеклянный шарик диаметром в 50 мм с входной и выходной трубками диаметром в 7 мм. Входная трубка расположена по касательной к поверхности шара таким образом, чтобы поток воздуха из трубки плавно, без изгибов іл поворотов, протекал бы на внутреннюю сферическую поверхность шарика. Так как по аэродинамическим законам согротивление трения между потоком воздуха и твердой поверхностью стекла меньше, чем трение потока воздуха о неподвижный окружающий воздух, то поток воздуха прильнет к поверхности стекла и даст внутри стеклянного шарика две вихреобразные дорожки, отчетливо видимые при эксперименте. При проникновении потока воздуха из узкой трубки (7 мм) 
в широкий шарик (50 мм) происходит внезапное уменьшение скорости, и дальше, при образовании вихревой дорожки, в центре ее получается еще большее замедление скорости движения, благодаря чему пыль из потока воздуха выпадает. Отверстие трубки для выхода обеспыленного воздуха

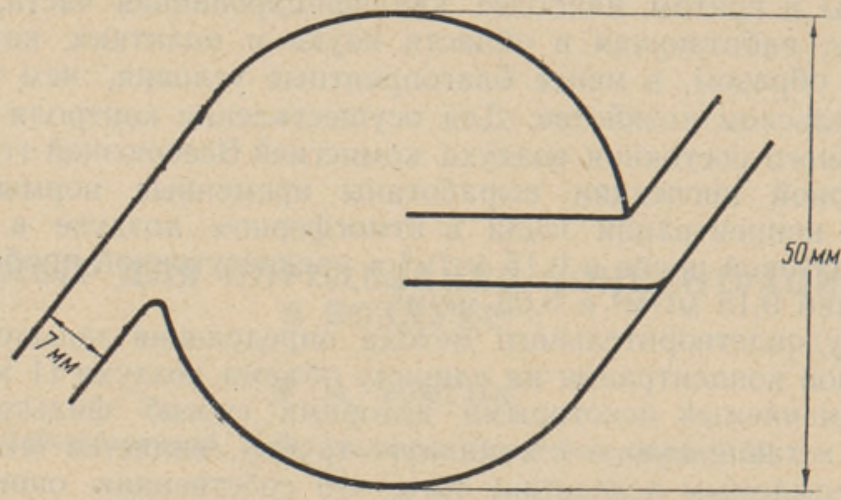

Рис. 1.

расположено в центре шарика, где скорость движения воздуха наименьшая, и поэтому из шарика уходит воздух, почти совершенно не содержащий пыли. Смазывать внутреннюю поверхность шарика какими-либо липкими жидкостями не требуется. Сушить шарики до опыта и доводить до постоянного веса также не требуется, так как наблюдаемое изменение веса ничтожно (в пределах сотых долей миллиграмма).

Скорость аспирации применялась в пределах 5-15 литров в минуту. Испытывались шарики с входными трубками в $3,5,5,0$ и 7,0 мм. Как видно из таблицы 1 , сопротивление, измеренное в миллиметрах водяного столба, при сужении трубки возрастает настолько, что при более узкой трубке делает почти невозможной аспирацию воздуха.

Количество уловленной в шарике пыли равнялось в среднем $96 \%$. При двух шариках, включенных последовательно, задержка пыли несколько повышается и доходит до $98 \%$. Следовательно, нет никакой надобности пользоваться двумя шариками, включенными последовательно, так как второй шарик улавливает весьма незначительное количество пыли, а сопротивление и время аспирации растут значительно.

Т аблица 1

\begin{tabular}{|c|c|c|c|c|}
\hline \multirow{4}{*}{$\begin{array}{c}\text { Диаметр } \\
\text { входной } \\
\text { трубки в мм }\end{array}$} & \multicolumn{4}{|c|}{$\begin{array}{c}\text { Сопротивление в мм водяного столба при скорости } \\
\text { аспирации в литрах в минуту }\end{array}$} \\
\hline & \multicolumn{4}{|c|}{ л/мин. } \\
\hline & 15 & 10 & 8 & 5 \\
\hline & \multicolumn{4}{|c|}{ мм вод. ст. } \\
\hline $\begin{array}{l}3,5 \\
5,0 \\
7,0\end{array}$ & $\frac{-}{16}$ & $\begin{array}{r}65 \\
40 \\
9\end{array}$ & $\begin{array}{l}44 \\
29 \\
-\end{array}$ & $\begin{array}{r}23 \\
14 \\
4\end{array}$ \\
\hline
\end{tabular}

То же при двух шарнках, включенных последовательно

\begin{tabular}{r|r|r|r|r}
3,5 & - & 98 & 72 & 40 \\
5,0 & - & 84 & 59 & 27 \\
7,0 & 28 & 15 & - & 7
\end{tabular}


Уловленная в шариках пыль имеет следующую дисперсность: менее 0,001 мм - 38\%, от 0,001 до 0,002 мм - 34\%, от 0,002 до 0,005 мм - $14 \%$ от 0,005 до 0,01 мм - $6 \%$ и более 0,01 мм - $8 \%$. В легкие при дыхании проникают пылинки размером не более 0,005 мм, следовательно $86 \%$ задерживаемой в шариках пыли способно проникать в легкие.

Для аспирации воздуха через шариковые фильтры использовались аккумуляторный аспиратор ${ }^{1}$, вакуум-насос, бытовой пылесос, металлический водоструйный насос, газо- и пароструйные эжекторы. Водоструйный насос необходимо включать в водопроводную сеть в подвале, где давление воды доходит до трех атмосфер (чем выше этаж, тем больше падает давление).

Для газоструйного эжектора была использована энергия испарения жидкой углекислоты из маленького стального баллона емкостью в один литр, общим весом около 4,5 кг. Для равномерного регулирования выхода углекислоты применялся редуктор или же кран Гофера. В газоструйном эжекторе отверстие для выхода углекислоты имело диаметр 0,4 мм, а конический раструб в ближнем конце - 4 мм, в дальнем конце - 15 мм. На просасывание одного литра воздуха расходовался один грамм жидкой углекислоты. Таким образом, одного килограмма жидкой углекислоты, помещающегося в нашем баллоне, хватало для просасывания 1000 литров воздуха. Малый баллон с жидкой углекислотой может служить переносным аспиратором для отбора не более одной пробы пыли. Такой баллон более удобен для отбора проб воздуха на загрязняющие его газы, так как в этом случае для одной пробы требуется всего несколько десятков литров, и поэтому емкости баллона хватает на несколько десятков проб. Большие же баллоны, емкостью в 20 литров, слишком тяжелые и для переноски неудобные, могут применяться для круглосуточной аспирации.

Для пароструйного эжектора был использован паровой котел емкостью в один литр, оборудованный манометром, водомерным стеклом и предохранителем. Нагревание котла производилось обычной керосинкой. Давление пара достигало полутора атмосфер при $125^{\circ}$. Пароструйный эжектор может быть полезным при отсутствии электроэнергии.

Работа выполнена в Ленинградском научно-исследовательском санитарно-гигиеническом институте при участии научного сотрудника В. В. Пресновой.

1 Н. М. Томсон и Е. К. Угрюмова-С апожнико,ва, К методам исследования загрязнения атмосферного воздуха, «Гигиена и санитария», № 6, 1947.

5 Tead. Akad. toimetised 4 